\title{
Effects of strict public health measures on seroprevalence of anti-SARS-CoV-2 antibodies during pregnancy
}

\author{
Hillary HY Leung, Christy YT Kwok, Daljit S Sahota, Maran BW Leung, Grace CY Lui, Susanna SS Ng,
} WC Leung, Paul KS Chan, Liona CY Poon *

\section{A B S T R A C T}

Introduction: A substantial number of people infected with severe acute respiratory syndrome coronavirus 2 (SARS-CoV-2) remain asymptomatic throughout the course of infection. Nearly half of pregnant women with coronavirus disease 2019 (COVID-19) are asymptomatic upon diagnosis; these cases are not without risk of maternal morbidity. Here, we investigated the seroprevalence of antiSARS-CoV-2 antibodies in an unselected sample of pregnant women in Hong Kong.

Methods: This prospective cohort study included pregnant women who presented for routine Down syndrome screening (DSS) between November 2019 and October 2020; all women subsequently delivered at the booking hospitals. Serum antibodies against SARS-CoV-2 were analysed using a qualitative serological assay in paired serum samples taken at DSS and delivery for all participants.

Results: In total, 1830 women were recruited. Six women $(0.33 \%)$ were seropositive at the DSS visit; this seropositivity persisted until delivery. Of the six women, none reported relevant symptoms during pregnancy; one reported a travel history before DSS and one reported relevant contact history. The interval between sample collections was 177 days (range, 161-195). Among women with epidemiological risk factors, $1.79 \%$ with travel

This article was published on 28 Jan 2022 at www.hkmj.org. history, $50 \%$ with relevant contact history, and $0.77 \%$ with community SARS-CoV-2 testing history, were

seropositive.

Conclusion: The low seroprevalence in this study suggests that strict public health measures are effective for preventing SARS-CoV-2 transmission. However, these measures cannot be maintained indefinitely. Until a highly effective therapeutic drug targeting SARS-CoV-2 becomes available, vaccination remains the best method to control the COVID-19 pandemic.

Hong Kong Med J 2022;28:294-9

https://doi.org/10.12809/hkmj219653
${ }^{1}$ HHY Leung, MB, BS, BSC
${ }^{1}$ CYT Kwok, BMBS
${ }^{1}$ DS Sahota, BEng, PhD
${ }^{1}$ MBW Leung, PhD
${ }^{2}$ GCY Lui, MB, ChB (Hons), PDiplD
${ }^{3}$ SSS Ng, MB, ChB, FHKAM (Medicine)
${ }^{4}$ WC Leung, MB, BS, MD (HKU)
${ }^{2}$ PKS Chan, MB, BS, MD (CUHK)
${ }^{1}$ LCY Poon *, MB, BS, MD (Res) (University of London)
1 Department of Obstetrics and Gynaecology, The Chinese University of Hong Kong, Hong Kong
2 Division of Infectious Diseases, Department of Medicine and Therapeutics, The Chinese University of Hong Kong, Hong Kong
${ }^{3}$ Division of Respiratory Diseases, Department of Medicine and
Therapeutics, The Chinese University of Hong Kong, Hong Kong
${ }^{4}$ Department of Obstetrics and Gynaecology, Kwong Wah Hospital, Hong Kong
* Corresponding author: liona.poon@cuhk.edu.hk

New knowledge added by this study

- The seroprevalence of severe acute respiratory syndrome coronavirus 2 (anti-SARS-CoV-2) antibodies in an unselected sample of pregnant women in Hong Kong was low.

- Public health measures are effective for limiting the transmission of SARS-CoV-2.

- Anti-SARS-CoV-2 antibodies persist for at least 6 months.

Implications for clinical practice or policy

- Serological testing could be utilised at antenatal screening to confirm the presence of anti-SARS-CoV-2 antibodies, preferably acquired through vaccination; such antibodies would provide some protection for the pregnant woman and her baby during the remaining portion of the pregnancy.

\section{Introduction}

A substantial number of people infected with severe acute respiratory syndrome coronavirus 2 (SARS$\mathrm{CoV}-2)$ remain completely asymptomatic throughout the course of infection. ${ }^{1}$ In a recent prospective observational study of maternal and neonatal complications among 2130 pregnant women with and without SARS-CoV-2 infection, $44 \%$ of pregnant women diagnosed with coronavirus disease 2019 (COVID-19) were asymptomatic upon diagnosis. 
Despite this asymptomatic status, they exhibited increased risks of maternal morbidity (relative risk $=1.24 ; 95 \%$ confidence interval $=1.00-1.52)$ and pre-eclampsia (relative risk $=1.63$; 95\% confidence interval $=1.01-2.63$ ), compared with pregnant women who had not been diagnosed with COVID- $19 .^{2}$ In a retrospective cohort study conducted in Spain, 3.1\% of 759 pregnant women exhibited anti-SARS-CoV-2 antibodies and had been asymptomatic throughout pregnancy. ${ }^{3}$ Serological testing may serve as a useful tool to identify pregnant women who have recovered from a recent asymptomatic SARS-CoV-2 infection; this information can help guide the management of potential future complications.

Before the imposition of strict border control, a large number of people travelled between Hong Kong and the rest of the world each day. Pregnant women could have been infected without their knowledge because of asymptomatic or very mild disease. Furthermore, pregnancy symptoms can mask some COVID-19 symptoms, particularly if the COVID-19 symptoms are mild. ${ }^{4}$ In this study, we invited women who had undergone Down syndrome screening (DSS) since November 2019 to ascertain the seroprevalence of anti-SARS-CoV-2 antibodies in an unselected sample of pregnant women in Hong Kong. The findings were expected to provide insights concerning the asymptomatic infection rate among pregnant women.

\section{Methods}

This prospective cohort study included pregnant women who presented for routine DSS and underwent routine blood sample collection at 11 to 13 weeks of gestation between November 2019 and October 2020. All participants delivered at Kwong Wah Hospital or Prince of Wales Hospital, Hong Kong; the last delivery occurred in March 2021. Eligibility criteria included consent to serum storage for future research purposes and intention to deliver at the booking hospital. Eligible women who attended the booking hospital for delivery were invited to participate in the study. Women who delivered elsewhere, experienced pregnancy termination or miscarriage, or received a diagnosis of COVID-19 before the study were excluded. Women who agreed to participate in the study were asked to provide written informed consent for blood collection at delivery. Symptoms of COVID-19 throughout the pregnancy were evaluated at recruitment and at delivery.

Serum antibodies against SARS-CoV-2 were analysed using a qualitative serological assay. Qualitative detection of anti-SARS-CoV-2 antibodies (immunoglobulin G [IgG] and immunoglobulin M [IgM]) directed against the nucleocapsid protein (N-protein) of the virus was performed using the Elecsys Anti-SARS-CoV-2 assay (Roche, United

\section{嚴格的公共衛生管理措施對孕期抗SARS-CoV-2 抗體血清陽性率的影響}

梁曉如、郭殷軕、Daljit S Sahota、梁寶華、雷頌恩、吳素珊、 梁永昌、陳基湘、潘昭願

引言：大量感染嚴重急性呼吸系統綜合症冠狀病毒2 (SARS-CoV-2) 的患者在整個感染過程中無出現症狀。儘管近一半感染2019冠狀病毒 病的孕婦在確診時為無症狀感染者, 這些病例仍存在孕產婦併發症的 發病風險。本研究旨在調查香港孕婦血清樣本中抗SARS-CoV-2抗體 陽性率。

方法：這項前瞻性隊列研究納入 2019 年 11 月至2020年10月期間進行 唐氏綜合症篩查的孕婦。所有孕婦均在預約醫院分娩。對所有參與此 項研究的孕婦在進行唐氏綜合症篩查時和分娩時採集血液樣本, 用定 性血清學測定法分析抗SARS-CoV-2血清抗體。

結果：共招募1830名孕婦, 其中六名孕婦（ $0.33 \% ）$ 在唐氏綜合症篩 查時抗SARS-CoV-2血清抗體呈陽性並持續到分婏。這六名孕婦在懷 孕期間均未出現感染SARS-CoV-2的相關症狀; 一名孕婦報告孕期旅 行史, 一名孕婦報告相關接觸史。孕婦血液樣本收集時間間隔為 177 天（介乎161-195天）。有流行病學危險因素的孕婦中， $1.79 \%$ 有旅行 史, $50 \%$ 有相關接觸史, $0.77 \%$ 有社區SARS-CoV-2檢測為血清抗體陽 性史。

結論：在本研究中, 低血清抗體陽性率表明嚴格的公共衛生管理措施 可有效預防SARS-CoV-2 傳播, 但這些嚴格的管理措施並不能無限期 維持下去。在出現針對SARS-CoV-2有效治療藥物前, 疫苗接種仍然 是控制2019冠狀病毒病大流行的最佳方法。
States) on a Cobas $^{\circledR}$ e411 analyser. The result was provided as a cut-off index (COI). A positive anti-SARS-CoV-2 antibody result was defined as COI $\geq 1.0$. Individuals who had recovered from COVID-19 were recruited as positive control cases (COI $\geq 1.0$ ); individuals who had negative SARS-CoV-2 test results were recruited as negative control cases $(\mathrm{COI}<1.0)$ to ensure quality control in the antiSARS-CoV-2 immunoassay.

Positive results based on qualitative detection of anti-SARS-CoV-2 antibodies were subsequently confirmed by quantitative measurements of IgG and IgM antibodies against the SARS-CoV-2 spike protein by using enzyme-linked immunosorbent assays (ImmunoDiagnostics Limited, Hong Kong). All tests were performed in duplicate, in accordance with the manufacturer's instructions. Results were interpreted as negative when the optical density was $<0.2$ and as positive when the optical density was $\geq 0.2$. For samples with positive results, anti-spike protein concentrations $(\mathrm{ng} / \mathrm{mL})$ were calculated.

Continuous variables were expressed as medians (interquartile ranges or ranges). Categorical variables were summarised as counts and percentages. SPSS Statistics (Windows version 26.0; IBM Corp, Armonk [NY], United States) was used for data analyses. 
The STROBE reporting guidelines were used during the preparation of this manuscript.

\section{Results}

In total, 3219 consecutive pregnant women were approached; 306 declined participation and 1083 were excluded, including two with laboratoryconfirmed SARS-CoV-2 infection, 69 who experienced miscarriage or pregnancy termination, and 1012 who planned delivery elsewhere. Thus, 1830 women were recruited to the study and provided written informed consent to participate. In total, 1810 (98.9\%) women were Chinese, and $852(46.6 \%)$ women were nulliparous. The median (interquartile range) maternal weight, height and age were $55.5 \mathrm{~kg}$ (50.3-62.5), $159 \mathrm{~cm}$ (155-163) and 33.0 years $(30.2-36.4)$, respectively.

In total, six women $(0.33 \%)$ were seropositive $(\mathrm{COI} \geq 1)$ at the DSS visit; this seropositivity persisted until delivery. Among these six women, one exhibited both anti-SARS-CoV-2 IgG and IgM antibodies; the IgM antibodies were undetectable at delivery. The remaining seropositive women exhibited only anti-SARS-CoV-2 IgG antibodies at both visits. All six of these women reported no relevant symptoms during pregnancy. Among the six women, one reported a travel history before her first DSS and one reported relevant contact history. The median COIs were 2.465 (interquartile range $=1.430-3.178$ ) and 1.680 (interquartile range $=1.145-2.350$ ) at DSS and delivery, respectively. The interval between sample collections was 177 days (range, 161-195). The COI at delivery was lower by a median of $31.8 \%$ (range, 12.0-35.1), compared with the COI at the DSS visit.

Characteristics of the study sample are presented in the Table. Fifty six women reported a travel history during pregnancy; one (1.79\%) was seropositive at both visits. Two women reported relevantcontacthistoryduring pregnancy;one(50.0\%) was seropositive at both visits. Forty two women reported relevant symptoms during pregnancy; all were seronegative at both visits. Of the 1788 asymptomatic women, six $(0.34 \%)$ were seropositive at both visits. In all, 259 women reported undergoing community SARS-CoV-2 testing during pregnancy; all tested negative. Among these 259 women, two $(0.77 \%)$ were seropositive at both visits.

\section{Discussion}

Our findings demonstrated a low seroprevalence (0.33\%) of anti-SARS-CoV-2 antibodies in an unselected sample of pregnant women in Hong Kong. Among women with risk factors for SARS-CoV-2 infection, $1.79 \%$ and $50 \%$ with a travel history and relevant contact history, respectively, were seropositive. This finding suggests that targeted

TABLE. Characteristics of the study sample*

\begin{tabular}{|c|c|c|c|c|c|}
\hline $\begin{array}{l}\text { COVID-19 history during } \\
\text { pregnancy }\end{array}$ & No. $(\%)[n=1830]$ & Antibody COI at DSS & $\begin{array}{l}\text { Seropositive at } \\
\text { DSS }\end{array}$ & $\begin{array}{c}\text { Antibody } \mathrm{COI} \text { at } \\
\text { delivery }\end{array}$ & $\begin{array}{l}\text { Seropositive at } \\
\text { delivery }\end{array}$ \\
\hline Travel history & $56(3.06 \%)$ & $0.080(0.071-0.089)$ & $1(1.79 \%)$ & $0.060(0.057-0.073)$ & $1(1.79 \%)$ \\
\hline Relevant contact history & $2(0.11 \%)$ & $0.081,3.230$ & $1(50.0 \%)$ & $0.066,2.480$ & $1(50.0 \%)$ \\
\hline Any relevant symptoms ${ }^{\dagger}$ & $42(2.30 \%)$ & $0.083(0.078-0.086)$ & 0 & $0.078(0.067-0.089)$ & 0 \\
\hline Cough & $14(0.77 \%)$ & $0.084(0.082-0.085)$ & 0 & $0.075(0.069-0.085)$ & 0 \\
\hline Sore throat & $12(0.66 \%)$ & $0.082(0.080-0.083)$ & 0 & $0.077(0.068-0.083)$ & 0 \\
\hline Runny nose/sneezing & $7(0.38 \%)$ & $0.078(0.071-0.081)$ & 0 & $0.091(0.083-0.091)$ & 0 \\
\hline Fever & $13(0.71 \%)$ & $0.085(0.083-0.088)$ & 0 & $0.076(0.070-0.084)$ & 0 \\
\hline Malaise & $2(0.11 \%)$ & $0.088,0.122$ & 0 & $0.065,0.091$ & 0 \\
\hline Rash & $2(0.11 \%)$ & $0.072,0.093$ & 0 & $0.058,0.059$ & 0 \\
\hline Headache & $1(0.05 \%)$ & 0.297 & 0 & 0.327 & 0 \\
\hline Diarrhoea & $3(0.16 \%)$ & $0.080(0.078-0.087)$ & 0 & $0.092(0.080-0.093)$ & 0 \\
\hline Vomiting & $2(0.11 \%)$ & $0.074,0.091$ & 0 & $0.070,0.084$ & 0 \\
\hline Dizziness & $2(0.11 \%)$ & $0.076,0.556$ & 0 & $0.092,0.475$ & 0 \\
\hline Asymptomatic & $1788(97.70 \%)$ & $0.083(0.078-0.089)$ & $6(0.34 \%)$ & $0.071(0.063-0.085)$ & $6(0.34 \%)$ \\
\hline $\begin{array}{l}\text { History of community SARS-CoV-2 } \\
\text { testing (all negative) }\end{array}$ & $259(14.15 \%)$ & $0.084(0.080-0.090)$ & $2(0.77 \%)$ & $0.084(0.071-0.091)$ & $2(0.77 \%)$ \\
\hline
\end{tabular}

Abbreviations: COI = cut-off index; COVID-19 = coronavirus disease 2019; DSS = Down syndrome screening; SARS-CoV-2 = severe acute respiratory syndrome coronavirus 2

* Data are shown as median (interquartile range), individual values, or No. (\%), unless otherwise specified

+ Participants were either asymptomatic or symptomatic with one or more relevant symptoms. Their travel history, relevant contact history, and SARS-CoV-2 test status were also recorded 
serological testing of pregnant women with a positive epidemiological link is useful for identifying women who have recovered from asymptomatic SARS-CoV-2 infection. A limitation of this study was that we relied on recruited individuals to recall COVID-19 symptoms throughout pregnancy, using only two recall time points: recruitment and delivery. This aspect may have introduced recall bias, particularly when COVID-19 symptoms could be non-specific and overlap with pregnancy symptoms. However, this limitation presumably did not have a large effect on the results because the seroprevalence of anti-SARS-CoV-2 antibody found in our unselected sample of pregnant women was very low. With a population of over 7 million, Hong Kong has largely been successful in controlling the transmission of SARS-CoV-2. Only 11981 confirmed or probable cases have been recorded since the beginning of the epidemic. ${ }^{5}$ Thus, it is reasonable that the number of asymptomatic SARS-CoV-2 infections has also been low; this low number of asymptomatic infections has led to a low seroconversion rate in pregnant women. Compared with other seroprevalence studies in pregnant women, the seroprevalence recorded in our study was substantially lower. The seroprevalence rates were $14 \%$ and $21 \%$ in Barcelona ${ }^{6}$ and southern Madrid ${ }^{3}$ (both in Spain), respectively. The low seroprevalence of anti-SARS-CoV-2 antibodies recorded in our study is presumably related to the implementation of a series of infection control strategies, including strict border control, mandatory quarantine for inbound travellers, mask wearing, and meticulous contact tracing. Hong Kong has learnt from its prior experience combating the SARS (severe acute respiratory syndrome) outbreak in 2003; accordingly, it implemented serious control measures early during the current epidemic. The Figure outlines the timeline of public health measures implemented during the first three waves of the epidemic in Hong Kong. By the end of March 2020, Hong Kong had closed its border to all incoming non-residents arriving from overseas and stopped transits through the city. All returning residents were subject to mandatory quarantine for 14 days; the quarantine period was extended to 21 days in December 2020. Locally, temporary closures of gyms, karaoke venues, clubs, and bars were periodically enforced, depending on the incidence of COVID-19. Dine-in service was forbidden from 6:00 pm to 5:00 am for several months, beginning in mid-July 2020. Mask wearing in public indoor areas and public transportation was also mandatory at that time. Notably, all seropositive cases in this study were first identified at the DSS visit between February 2020 and July 2020. This suggests that the seropositive cases acquired their infections during the first two waves of the epidemic; the implementation of stricter control

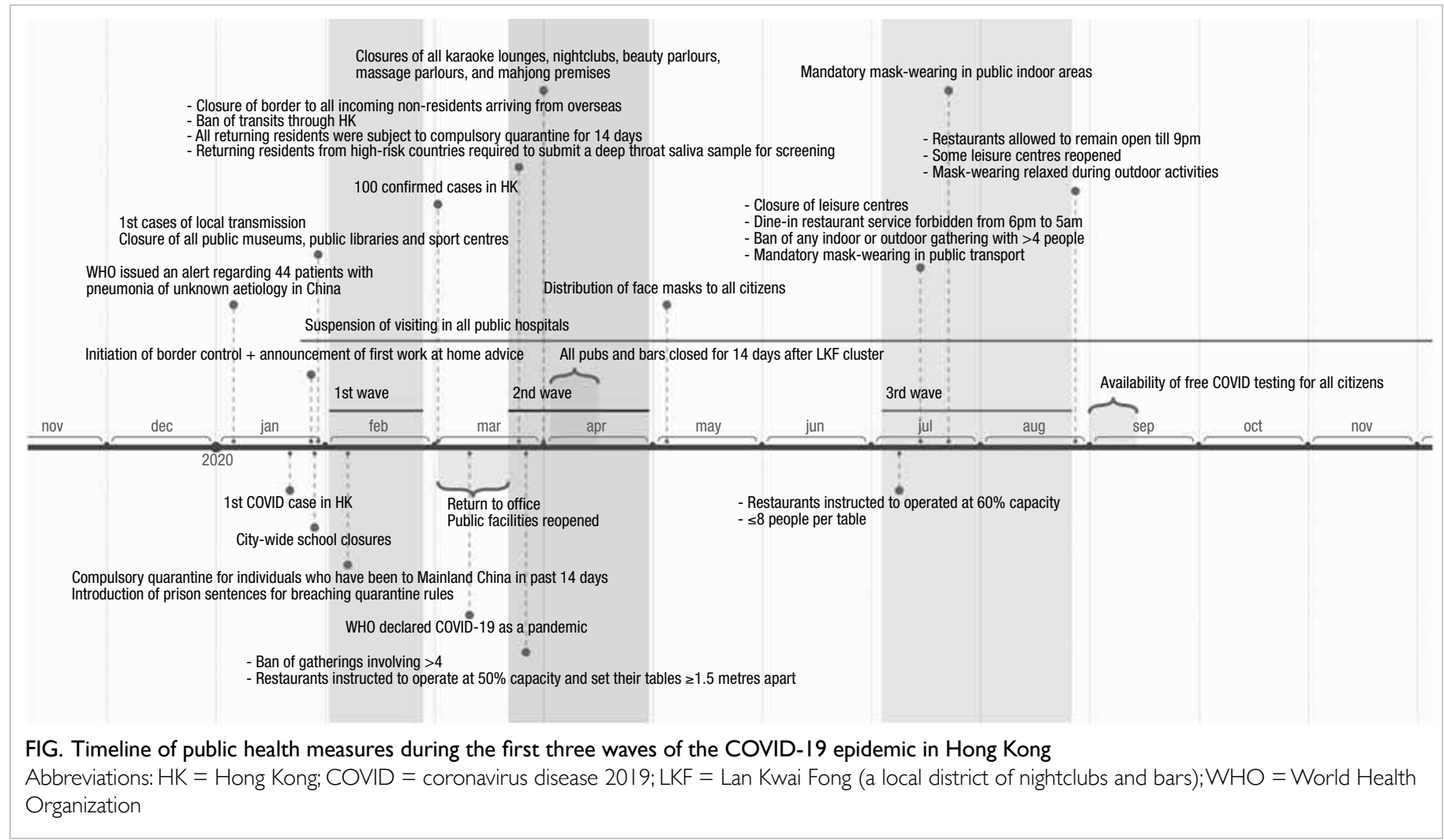


measures by the local government during the third wave might have led to a lower transmission rate of asymptomatic infection among pregnant women, resulting in a lack of seroconversion during that period. Moreover, pregnant women are presumably more careful about social distancing and compliant with public health regulations. It would be useful to compare our seroprevalence results with the findings in other countries where strict measures were also implemented, such as Australia and New Zealand.

The humoral immune response is characterised by the production of virus-specific neutralising antibodies. Regardless of whether patients are symptomatic, IgG or IgM seroconversion has been observed in $65 \%$ to $100 \%$ of patients after infection with SARS-CoV-2. ${ }^{7-10}$ We previously demonstrated that $75 \%$ of pregnant women with laboratory-confirmed SARS-CoV-2 infection were seropositive at delivery. ${ }^{11}$ In addition to the strict control measures mentioned above, the low seroprevalence recorded in our study might have been related to undetectable antibody levels at the time of specimen collection-the timing of blood sample collection might not have been compatible with antibody detection. However, this is unlikely to have affected the findings among the large number of pregnant women in this study. A longitudinal study conducted in Wuhan, China, demonstrated that the median times from the first virus-positive test result to IgG or IgM seroconversion were 7 and 14 days in asymptomatic and symptomatic patients, respectively. ${ }^{12}$ In the asymptomatic cohort, all patients underwent seroconversion within 14 days from the first positive reverse transcriptasepolymerase chain reaction result. ${ }^{12}$ While waning immunity was observed at 5 months after infection, ${ }^{13}$ two studies showed that the antibody levels remained high and detectable at 8 months after infection. ${ }^{14,15}$ This finding is consistent with our results that the antibodies persisted until delivery in all women who had demonstrated seroconversion at the DSS visit. Because the two blood samples in this study were collected approximately 6 months apart, the timing of specimen collection was presumably adequate to identify most women who had contracted SARSCoV-2 and developed detectable levels of antibodies.

Concerns regarding the usefulness of serological testing have been raised because of the uncertain onset and duration of humoral immunity; our study demonstrated a very low seroconversion yield in an unselected sample of pregnant women. Because of the ongoing vaccination programme, it is increasingly difficult to distinguish people who have acquired humoral immunity through natural infection from people who have acquired humoral immunity through vaccination. While the strict public health measures in Hong Kong have significantly reduced community transmission of SARS-CoV-2, these measures cannot be maintained indefinitely. The adverse effects of prolonged social distancing measures on the economy, education, mental health, and well-being of the population are immeasurable. There is increasing evidence that the COVID-19 mRNA vaccines are safe and effective; thus, pregnant women and women planning to become pregnant are encouraged to undergo vaccination at the earliest opportunity because pregnancy is a risk factor for severe COVID-19-related complications (eg, intensive care unit admission, invasive ventilation requirement, and death). ${ }^{16,17}$ The risk of preterm birth is also greater among pregnant women with COVID-19, compared with pregnant women who do not have COVID-19. ${ }^{18-20}$ Our study has demonstrated that anti-SARS-CoV-2 antibodies found at DSS persist until delivery. This result suggests that the presence of anti-SARS-CoV-2 antibodies in early pregnancy, preferably acquired through vaccination, would provide some protection for the pregnant woman and her baby during the remaining portion of the pregnancy.

Until a highly effective therapeutic drug targeting SARS-CoV-2 becomes readily available, mass vaccination remains the best solution to control the COVID-19 pandemic, avoid further lockdowns, and allow a return to "normal" pre-COVID-19 life, as well as saving lives. Our study highlights the importance of a successful vaccination campaign.

\section{Author contributions}

Concept or design: LCY Poon, DS Sahota.

Acquisition of data: HHY Leung, CYT Kwok, WC Leung, DS Sahota, MBW Leung, GCY Lui, SSS Ng.

Analysis or interpretation of data: HHY Leung, CYT Kwok, LCY Poon.

Drafting of the manuscript: HHY Leung, CYT Kwok, LCY Poon, DS Sahota.

Critical revision of the manuscript for important intellectual content: HHY Leung, CYT Kwok, LCY Poon, DS Sahota, SSS $\mathrm{Ng}$, PKS Chan.

All authors had full access to the data, contributed to the study, approved the final version for publication, and take responsibility for its accuracy and integrity.

\section{Conflicts of interest}

LCY Poon has received speaker fees and consultancy payments from Roche Diagnostics and Ferring Pharmaceuticals. She has also received in-kind contributions from Roche Diagnostics. Other authors have disclosed no conflict of interest.

\section{Acknowledgement}

We thank Lijia Chen, Tracy CY Ma, Maggie Mak, Ching-man Mak, Angela ST Tai, Jeffery Ip, Phyllis Ngai, Andrea Chan, and Lisa LS Chan for making substantial contributions by involving in study coordination and patient recruitment. 


\section{Funding/support}

This work was supported by Roche Diagnostic, United States, which provided reagents for the qualitative detection of antiSARS-CoV-2 antibodies.

\section{Ethics approval}

Approval for the study was obtained from the Joint Chinese University of Hong Kong-New Territories East Cluster Clinical Research Ethics Committee (CREC Ref No. 2020.214). Patients provided written informed consent to participate in the study; this included consent for serum storage for research purposes.

\section{Trial registration}

The study is registered with ClinicalTrials.gov (Ref NCT04465474).

\section{References}

1. Byambasuren O, Cardona M, Bell K, Clark J, McLaws ML, Glasziou P. Estimating the extent of asymptomatic COVID-19 and its potential for community transmission: systematic review and meta-analysis. Off J Assoc Med Microbiol Infect Dis Can 2020;5:223-34.

2. Villar J, Ariff S, Gunier RB, et al. Maternal and neonatal morbidity and mortality among pregnant women with and without COVID-19 infection: the INTERCOVID multinational cohort study. JAMA Pediatr 2021;175:81726.

3. Villalaín C, Herraiz I, Luczkowiak J, et al. Seroprevalence analysis of SARS-CoV-2 in pregnant women along the first pandemic outbreak and perinatal outcome. PLoS One 2020;15:e0243029.

4. Afshar Y, Gaw SL, Flaherman VJ, el al. Clinical presentation of coronavirus disease 2019 (COVID-19) in pregnant and recently pregnant people. Obstet Gynecol 2020;136:111725.

5. Hong Kong SAR Government. Together, we fight the virus! Available from: https://www.coronavirus.gov.hk/eng/ index.html. Accessed 28 Jul 2021.

6. Crovetto F, Crispi F, Llurba E, Figueras F, Gómez-Roig MD, Gratacós E. Seroprevalence and presentation of SARSCoV-2 in pregnancy. Lancet 2020;396:530-1.

7. Wölfel R, Corman VM, Guggemos W, et al. Virological assessment of hospitalized patients with COVID-2019. Nature 2020;581:465-9.

8. Zhao J, Yuan $\mathrm{Q}$, Wang $\mathrm{H}$, et al. Antibody responses to SARS-CoV-2 in patients with novel coronavirus disease 2019. Clin Infect Dis 2020;71:2027-34.
9. Long QX, Liu BZ, Deng HJ, et al. Antibody responses to SARS-CoV-2 in patients with COVID-19. Nat Med 2020;26:845-8.

10. Qu J, Wu C, Li X, et al. Profile of immunoglobulin G and IgM antibodies against severe acute respiratory syndrome coronavirus 2 (SARS-CoV-2). Clin Infect Dis 2020;71:22558.

11. Poon LC, Leung BW, Ma T, et al. Relationship between viral load, infection-to-delivery interval and mother-tochild transfer of anti-SARS-CoV-2 antibodies. Ultrasound Obstet Gynecol 2021;57:974-8.

12. Jiang $\mathrm{C}$, Wang $\mathrm{Y}, \mathrm{Hu} \mathrm{M}$, et al. Antibody seroconversion in asymptomatic and symptomatic patients infected with severe acute respiratory syndrome coronavirus 2 (SARS-CoV-2). Clin Transl Immunology 2020;9:e1182.

13. Choe PG, Kang CK, Suh HJ, et al. Waning antibody responses in asymptomatic and symptomatic SARS-CoV-2 infection. Emerg Infect Dis 2021;27:327-9.

14. Hartley GE, Edwards ES, Aui PM, et al. Rapid generation of durable B cell memory to SARS-CoV-2 spike and nucleocapsid proteins in COVID-19 and convalescence. Sci Immunol 2020;5:eabf8891.

15. Choe PG, Kim KH, Kang CK, et al. Antibody responses 8 months after asymptomatic or mild SARS-CoV-2 infection. Emerg Infect Dis 2021;27:928-31.

16. UK Government. JCVI issues new advice on COVID-19 vaccination for pregnant women. Available from: https:// www.gov.uk/government/news/jcvi-issues-new-adviceon-covid-19-vaccination-for-pregnant-women. Accessed 17 May 2021.

17. Hong Kong College of Obstetricians and Gynaecologists. HKCOG advice on Covid-19 vaccination in pregnant and lactating women (interim; updated on 21 April 2021). Available from: https://www.hkcog.org.hk/hkcog/Upload/ EditorImage/20210423/20210423141055_6024.pdf. Accessed 17 May 2021.

18. Martinez-Portilla RJ, Smith ER, He S, et al. Young pregnant women are also at an increased risk of mortality and severe illness due to coronavirus disease 2019: analysis of the Mexican National Surveillance Program. Am J Obstet Gynecol 2021;224:404-7.

19. Martinez-Portilla R, Sotiriadis A, Chatzakis C, et al. Pregnant women with SARS-CoV-2 infection are at higher risk of death and pneumonia: propensity score matched analysis of a nationwide prospective cohort (COV19Mx). Ultrasound Obstet Gynecol 2021;57:224-31.

20. Allotey J, Stallings E, Bonet M, et al. Clinical manifestations, risk factors, and maternal and perinatal outcomes of coronavirus disease 2019 in pregnancy: living systematic review and meta-analysis. BMJ 2020;370:e3320. 